\title{
Hyperthyroidism in Indonesian community: a mini review
}

\begin{abstract}
Community based research on hyperthyroidism in Indonesia was still a little. In 2007, based on Indonesian Basic Health Research, the prevalence of hyperthyroidism in urban was $6.9 \%$ (with TSH cut-off level $<0.55 \mathrm{mIU} / \mathrm{L}$ ). Education in community about hyperthyroidism is still less in Indonesia and must be increased.
\end{abstract}

Keywords: hyperthyroidism, prevalence, etiology, Indonesian

\section{Introduction}

Hyperthyroidism is a clinical condition caused by increased synthesis and secretion of hormones by the thyroid gland which affects the entire body with high metabolism. The presenting symptoms are not specific, so difficult to diagnose hyperthyroidism in its early stages without the aid of laboratory data. We did the literature review from searching PubMed and Google scholar using the search terms "hyperthyroidism prevalence or etiology or guideline.

\section{Prevalence}

Community based research on hyperthyroidism in Indonesia was still a little. In 2007, based on Indonesian Basic Health Research, the prevalence of hyperthyroidism in urban was $6.9 \%$ ( with TSH cut-off level $<0.55 \mathrm{mIU} / \mathrm{L}){ }^{1,2}$ Furthermore based on National Health Survey 2013 in the population at aged 15years and above, by interviewing 722,329 respondents whether diagnosed hypertyroidism or not by the doctors, were obtained the prevalence of hyperthyroidism in urban rural was $0.4 \%$, which urban $(0,5 \%)$ was more than rural $(0.4 \%)$, higher in high economic $(0,5 \%)$ than low $(0,3 \%)$ and aged $>45$ years $(0,5 \%)$ more than age $<45$ years $(0.4 \%){ }^{3}$

Hyperthyroidism was not included in the 20 leading causes of death at all ages in Indonesia just as in the world, ${ }^{4}$ so hyperthyroid is not as popular as coronary heart disease or stroke which is the main causes. In UK and US thyroid disease were common in females, affecting around $2 \%$ of women and $0.2 \%$ of men. ${ }^{5,6}$ Vander pump MPJ et $\mathrm{al}^{7}$ based on the data from screening large population samples from USA and Europe found the prevalence of hyperthyroidism in women was between 0.5 and $2 \%$, and was 10 times more common in women than in men in iodine-replete communities. ${ }^{7}$ Tahir MB et al found hyperthyroidism at age group from 25-34 years was the most frequent. ${ }^{8}$ Das A et al found the prevalence of hyperthyroidism in Manipur area (India) was $13.7 \%$, women more than man. ${ }^{9}$ Women are more desirable to different hormonal leaps, their body is very sensitive to any hormonal changes than male body. ${ }^{9}$ The prevalence of hyperthyroidism depend on ethnic, geographic, and environmental factors, which include the iodine intake status. ${ }^{10}$

\section{Etiology}

Research about the causes of hyperthyroid in Indonesian community has not been done, but has been known Grave's Disease that an autoimmune disease is the most cause of hyperthyroid in the world.
Volume 7 Issue 2 - 2019

\author{
Laurentia Mihardja, Muhammad Karyana \\ National Institute of Health Research and Development, \\ Indonesia
}

Correspondence: Laurentia Mihardja, National Institute of Health Research and Development, Jakarta, Indonesia,

Tel 08164824I73,Email laurentialitbang@yahoo.com

Received: November 15, 2018 | Published: March 18, 2019
Graves' hyperthyroidism is caused by genetic ( $80 \%$ of susceptibility) and environmental ( $20 \%$ of susceptibility) factors, including smoking, infection, stress and pregnancy. ${ }^{6}$ Smoking and exposure of cigarette smoke are more susceptible for Grave's Disease and need attention due to the prevalence of daily smoking in Indonesia was high at $24.3 \% .^{3}$ Less commonly, other causes of hyperthyroidism include: Thyroid nodules, Subacute thyroiditis, Lymphocytic thyroiditis and Postpartum thyroiditis. ${ }^{10}$

\section{Guidelines about diagnosis and therapy}

The guidelines were developed by The Indonesian Society of Endocrinology Task Force on Thyroid Diseases for diagnostic evaluation, therapy and management of hyperthyroidism in the adult population. ${ }^{1}$ Education in community about hyperthyroidism is still less in Indonesia and must be increased.

\section{Conclusion}

The prevalence of hyperthyroidism in urban Indonesia was $6.9 \%$. Smoking and exposure of cigarette smoke are more susceptible for Grave's Disease was high at $24.3 \%$. The guidelines about hyperthyroidism were developed by The Indonesian Society of Endocrinology Task Force on Thyroid Diseases.

\section{Acknowledgments}

We are grateful to the Director General of the National Institute of Health Research \& Development and the Director for Health Resources and Services who facilitated us to get the data. We thank the Experts Team of Riskesdas, Surveyors and Laboratory Team for the data survey, respondents and many people were involved in facilitating the findings in this study.

\section{Conflicts of interest}

The authors have no conflicts of interest to disclose.

\section{References}

1. The Indonesian Society of Endocrinology Task Force on Thyroid Diseases. Indonesian Clinical Practice Guidelines for Hyperthyroidism. Journal of the Asean Federation of Endocrine Societies. 2012;27:1.

2. Ministry of Health and National Institute of Health Research and Development. Report of Biomedical Basic Health Research. Jakarta, Indonesia: NIHRD; 2009. 
3. Ministry of Health and National Institute of Health Research and Development. National Report on Health Research. Riskesdas, 2013. Jakarta, Indonesia: NIHRD; 2014

4. WHO. The global burden of disease 2004 update. Geneva: WHO; 2008

5. K Boelaert K, Franklyn JA. Thyroid hormone in health and disease. $J$ Endocrinol. 2005;187:1-15.

6. Golden SH, Robinson KA, Saldanha I et al. Clinical review: prevalence and incidence of endocrine and metabolic disorders in the United States: a comprehensive review. J Clin Endocrinol Metab. 2009;94(6):18531878

7. Vanderpump MPJ. The epidemiology of thyroid disease. Br Med Bull. 2011;99:39-51.
8. Tahir MB, Kolawole A, Bakari Aa, et al. The Prevalence of Hyperthyroidism At University Of Maiduguri Teaching Hospital (Umth), Maiduguri. Kanem Journal of Medical Sciences. 2014;(8)1:1318

9. Das A, Shaini L, Sangeeta N, et al. Prevalence of Thyroid Hormone Dysfunction among Female Patients, Attending A Multispeciality Hospital In Manipur. IOSR Journal of Dental and Medical Sciences. 2013;10(2):7-11

10. Cooper D, Dermott MM, Wartofsky L. Hyperthyroidism. J Clin Endocrinol Metab. 2006;91(7):E2. 